\title{
An analysis on university preparatory class students' views about role of English as a foreign language on world knowledge, education and professional career ${ }^{12}$
}

\author{
Yasin Turan \\ Abdullah Gul University, Turkey; ysn38trn38@hotmail.com
}

\begin{abstract}
People all around the world learn different foreign languages for various reasons. As a result of globalization, need for knowing a language other than one's native language became a necessity more than a need. Although there are thousands of languages used by millions of people in different geographies, some languages are more commonly used and preferred. English, which is used as a lingua franca in many fields including science, education and numerous branches of business, is one of these languages. Turkey, as a country that serves as a bridge between Asia and Europe, has gone through many reforms concerning foreign language teaching and today foreign languages are taught in every phase of education starting from early years of primary school and continues until students graduate from university. Although people have different reasons to learn a foreign language, it is very common among university students that most of them learn a foreign language for a better future as well as increasing their world knowledge in a fast-globalized world. In this study, it is aimed to analyze university prep class students' views about role of English as a foreign language for enhancing their world knowledge and success in education and professional career. The results of the study reveal that students accept English as lingua franca and they are enthusiastic to learn it. Another finding underlines the need for ESP (English for Specific Purposes) courses expressed by prep students.
\end{abstract}

Keywords: foreign languages, English, world knowledge, education, professional career

\section{Introduction}

It is a well-known fact that today's globalized world demands more competitiveness, entrepreneurship and productivity from people more than it did in the past. Therefore, people are looking for opportunities that will contribute to their personal development, education and social skills. Although there are many ways to do so, especially in Turkey, learning a foreign language is regarded as one of the most important tools for success in many fields. As a result, Turkey has been implementing some policies regarding foreign language teaching for years and encouraging people to learn at least one foreign language. This point of view has also been reflected in national education policy and being updated according to political, economic, scientific and technological developments in a global scale as well as country's needs. In order to fully understand Turkish people's point of views about learning a foreign language and to comment this study's results, it is useful to take a glance at the processes that Turkish education system has been going through in terms of foreign language teaching.

First attempts for teaching a foreign language began with the Tanzimat Period and many scientists and teachers were invited from different countries including France and Germany. As a result, westernization process began especially with the great influence of French culture. Therefore, French was the dominant foreign language taught at schools until the second half of $19^{\text {th }}$ century. Second World War was one of the breaking points in many ways all around the world. Turkey was also deeply affected by the results of the war in many ways. Both British and American dominance on trade, science and technology was so apparent that English became the most common language used all around the world. As a result of growing political and military relationships between Turkey and USA, English became the most preferred foreign language.

Policies and regulations in order to meet the need for learning English as a foreign language were developed and basic law of Foreign Language Teaching regulating the issues regarding teaching foreign languages was enacted in 1983. The aim of this law was to regulate implementation of principles

${ }^{12}$ This paper was presented at the Educational Role of Language Conference Vilnius, Lithuania, June 14-15, 2018 
regarding teaching a foreign language at schools (Mevzuat 2018). After the second half of 1980s, foreign language education went through various changes. For example, until 1988, English, French and German were taught and students were supposed to choose one of them as a compulsory lesson. However, in 1989 foreign languages lessons were not taught as compulsory lessons, but electives. The reason behind this decision was establishing some special schools under the name of "Anatolian High Schools" in which some courses (Math, Biology, Chemistry, etc.) were taught in English.

Since these schools were important for increasing students' English level, a great number of Anatolian High Schools were established all around the country leading some problems such as hiring enough number of qualified English teachers who can teach a lesson in English. In 1992, the idea of Anatolian High Schools was evolved and a new type of school called "Super High School" were established and students were given 24 hours of English in preparatory class for a year. After preparatory class, intensive English teaching continued until students graduate from high school. As a graduate of "Super High School", I believe that the idea of preparatory class before $9^{\text {th }}$ grade was very successfully implemented and students, including me, benefited from the curriculum implemented in Super High Schools.

One of the most important steps taken to improve the effectiveness of English language teaching was including English courses into primary school curriculum. Starting from 1997-1998 Academic Year, $4^{\text {th }}$ graders were taught English 2 hours a week. In 2014, the idea of raising awareness for learning a foreign language during early years of education was taken one step further and 2 hours of English course were included into $2^{\text {nd }}$ graders curriculum. As it can be inferred from the information given so far, foreign language awareness and especially the importance of learning English as a lingua franca today has increased year by year and students are exposed to significant amount of English before they graduate from high school and begin their higher education.

English has an important role in higher education and factors such as students' backgrounds, levels, perceptions and interests in terms of English as a foreign language influence the success of learning English at universities. Therefore, in the direction of decision taken by Turkish Council of Higher Education (YOK), no matter what students' English level is, English is taught as a compulsory course in the $1^{\text {st }}$ academic year (Yaman 2015). However, according to Turkish Council of Higher Education (YOK 2018) there are 206 public and private universities in Turkey and these universities may implement different policies regarding English language teaching. In most of the public universities medium of instruction is mostly Turkish but there are some public and private universities that use English as the medium instruction. For these universities, preparatory classes are very important and students are given at least 1 year of intensive English courses so that they can follow their faculty courses easily.

The brief explanation given so far about students' English journey in their formal education shows that Turkish students are exposed to a great amount of English language teaching and they have enough background to express ideas on their perceptions, thoughts and feelings about learning English as a foreign language. In this regard, many studies were carried by different researchers in order to find out different dimensions of students' views about learning English from different levels ranging from primary school to university. In one of the studies conducted in order to reveal university students' attitudes towards learning English, Gokyer and Bakcak (2014) mostly focused on affective factors such as interest and confidence by taking different variables such as students' ages, previous school types and faculties into consideration.

In another study, Pan and Akay (2015) aimed to examine students' attitudes and classroom anxiety levels towards foreign language courses at faculty of education and they found out that participants have positive attitudes towards learning English while no significant correlation between students' attitudes and their previous school types was found. Another finding which may also be related to the topic of this study shows that following English publishing and broadcasts affect students' cognitive and affective manners and students who like following these sources tend to have positive attitudes towards learning English. 
Motivation also plays an important role on prep students' English learning journey. The motivations of learning English are incentives for preparatory students to achieve targets. These targets may vary from advancing into the college study to choosing an ideal major. As a matter of fact, the motivations for them to learn English are diverse. The graph below presents some motivational factors for learning English from prep students' points of view (Li, Ma \& Wang 2013).

Figure 1: Motivations for learning English.

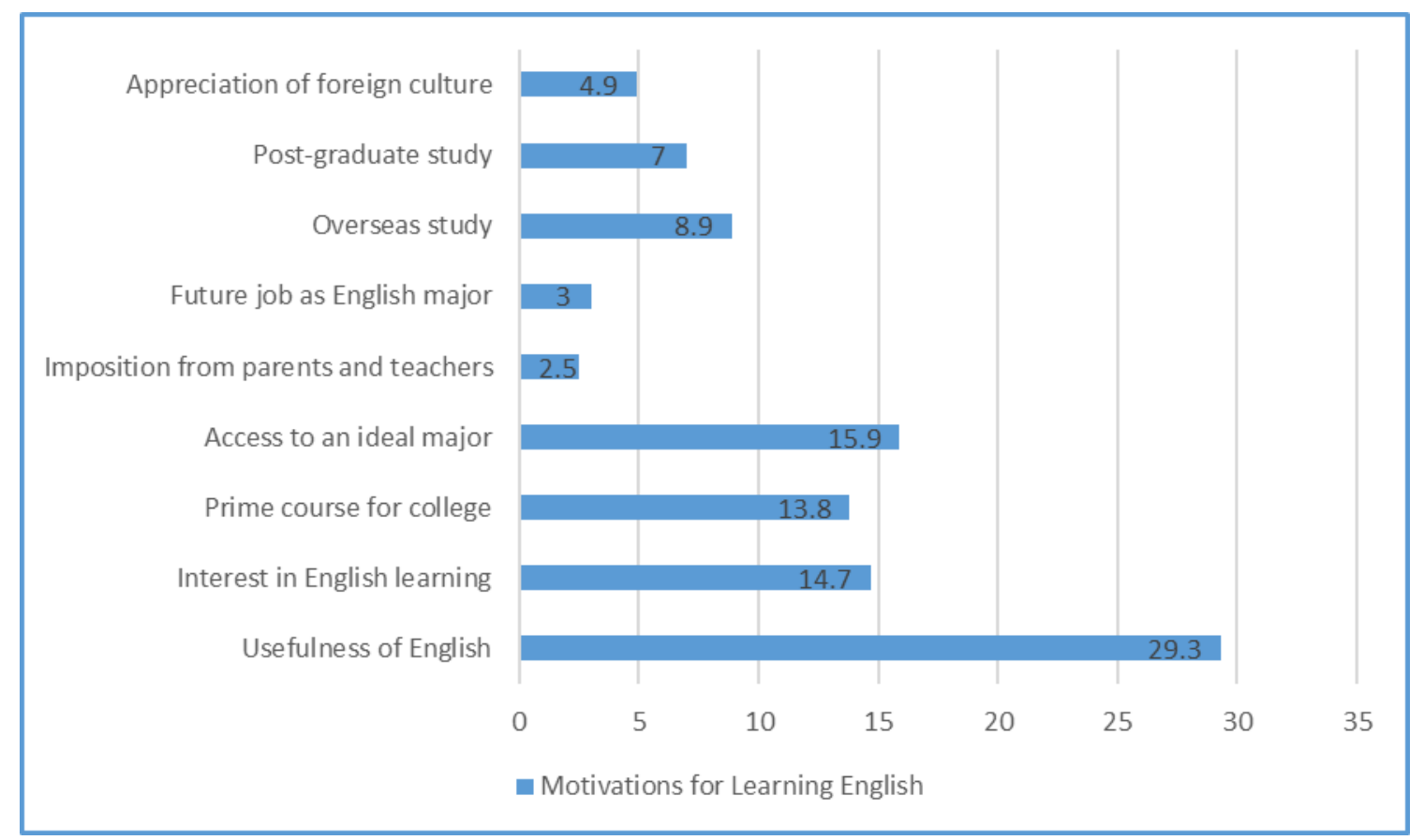

In another study, Yurtseven, Altun and Aydın (2015) found another affective factor which influences prep students' attitudes towards learning English. They found out that creating a nonthreatening atmosphere while teaching English have a positive effect on prep class students' learning process. In his study, Abdulhafidh (2015) focuses on the importance of learning English in present day higher education. He underlines the fact that regardless of the country, the medium of instruction and subjects studied, English is always in the center of the studies or education. For internationalization of higher education, English is not only locally but globally required as an important source of accessing students' major knowledge in all field as well as communicating with the most reputed universities worldwide English is also a medium in pursuing a variety of degree programs and finding high-quality jobs and positions in educational institutions and foreign companies elsewhere.

As it was mentioned before, there are so many studies both in Turkey and all around the world about students' attitudes towards learning English. However, it is also a need to reveal some other dimensions regarding particularly university students' views and perceptions about the role of English as a medium to increase their world knowledge and success in both education and professional career. Therefore, this study aims to provide an insight on university students' views regarding English's role for enhancing their world knowledge and success in education and professional career.

\section{Methodology}

In this study, qualitative research method was used. Corbin and Strauss (2015: 5) define qualitative research as "a form of research in which the researchers or a designated co-researcher collects and interprets data, making the researcher as much as part of the research process as the participants and 
data they provide". According to definition given by Yıldırım and Şimşek (2013: 45), qualitative researches are the ones that include methods such as observations, interviews and document analysis aiming to collect data about perceptions and events that happen in their natural environment in a natural sequence. In this regard, interviews are one of the most commonly used data collection methods used by researchers designing a qualitative research.

During data collecting process, semi-structured interviews were used in this study. Semi-structured interviews save a great amount of time since they allow researchers for coding and analyzing the data in a fast way and they are helpful for comparing the similarities and differences between data collected by different interviewees participating in the research (Büyüköztürk et al., 2008). In this study, twelve questions asked during interviews were grouped into three categories as following:

1. What are preparatory students' views about the role of English in terms of contributing to their world knowledge?

2. What are preparatory students' views about the role of English in their current and future education?

3. What are preparatory students' views about the role of English in professional career?

Questions were checked by two different researchers in terms of questions' comprehensibility and relevance with the topic and they were rephrased by taking researchers" feedbacks into consideration. Participants of this study are 10 preparatory class students from different faculties studying at Abdullah Gul University School of Foreign Languages as given in Table 1 below.

Table 1: Demographic information about participants.

\begin{tabular}{|c|c|c|c|}
\hline Participant & Age & Gender & Faculty \\
\hline Student-1 & 19 & Male & Engineering \\
\hline Student-2 & 20 & Male & Architecture \\
\hline Student-3 & 20 & Male & Engineering \\
\hline Student-4 & 19 & Female & Management \\
\hline Student-5 & 19 & Female & Engineering \\
\hline Student-6 & 21 & Male & Management \\
\hline Student-7 & 20 & Female & Engineering \\
\hline Student-8 & 19 & Female & Architecture \\
\hline Student-9 & 19 & Male & Management \\
\hline Student-10 & 20 & Female & Architecture \\
\hline
\end{tabular}

A simple random sampling technique was used for selecting the participants since this technique provides equal chances to be selected for all the individuals in the population (Karasar 2006: 113). Questions were asked in an order and answers were recorded by a voice recorder. After recording procedure, answers were transformed into word format word by word by giving each student a code starting with abbreviation of student (S) and a number from 1 to 10 . After scripts were created, descriptive method was used in order to analyze the collected data. In descriptive analysis, collected data is summarized and commented according to categories and themes identified in advance. Students' answers were analyzed by using the themes that are embedded in the research topic. These themes are; world knowledge, current and future education and professional career. After that, the findings are defined and commented by the researcher. In order to emphasize participants' views on a given question, researchers may use direct citations from their answers by explaining cause and effect relations as well as comparing the answers given by different participants (Yıldırım \& Şimşek 2013: 256). Therefore, direct citations are frequently used during this study. 


\section{Findings}

In this section, participants' views gathered by twelve questions asked under three main categories will be presented.

\section{Students' views about relationship between English and world knowledge}

The questions asked in the first category focused on students' views about the role of English in contributing to their world knowledge and 4 questions were addressed to the participants in order to get their detailed comments. First question in this category was "How does English contribute to enhancing your world knowledge?". While answering this question, most of the participants underlined the universality of English and they indicated that English is the most useful tool to learn more about not only American or British culture, but also about other cultures whose native language is not English. For example, S2 says: "Although Spanish is a language used by millions of people all around the world, we can see that many Spanish websites use English as the first language since they know that they can reach more people this way. It shows that even if we don't know a specific country's language, we can still learn about their lifestyles, folklores, and cultures thanks to English".

Another important theme underlined by the participants was "reliability of the cultural sources" provided by using English while searching about a country's culture instead of referring to secondary or translated sources. S5's answer can be given as an example for this theme. He says: "Language is a vital part of a culture. If we learn language of a country we can also learn about its culture. Of course, it is impossible to learn every language spoken by different cultures but here English's universality comes into play. If we learn English we can learn about any culture at first hand without needing translation or interpretation by a second party and this increases the reliability of knowledge we access about a specific culture".

The second question in this category was "What is your opinion about including cultural elements into curriculums and classroom activities?" While answering this question, most of the students underlined the "necessity" of including cultural items into all types of teaching activities mentioning the fact that learning a culture facilitates learning a foreign language. S3 clarifies this opinion by saying "This situation is not limited with only English language. In order to learn English, we should also learn the cultures of other countries whose native language is English. I want to give an example from my own experience. Last term, I chose 2 elective courses about Canadian and English cultures. My interest in these two cultures increased my interest in languages spoken by people living in these countries. In addition to this, I never felt bored while studying English since learning about a different culture made language learning process more enjoyable".

On the other hand, S10 draws the attention to the importance of two important linguistic elements which are idioms and proverbs that also carries cultural components. She says: "I have been learning English for a while and idioms and proverbs are important component in a language since they have cultural connotations. Even if I understand a given idiom or proverb lexically, most of the times I have difficulties in interpreting them in a cultural context. Therefore, lexical and linguistic elements should also be clarified by cultural inputs and this makes including cultural elements into teaching activities necessary". Although all of the participants are positive about learning cultural components while learning English, two of them mentioned some concerns about the risk of undervaluing their national culture. For example, S1 says: "Learning something about a different culture can be appealing for many people and doing this by using English facilitates learning both English and English culture. However, my concern is that being exposed to a different culture too often may cause especially young learners undervalue their own culture. Therefore, while learning a different culture, we should also make sure that students are learning about their own culture as much as possible".

The third question belonging to the first category of the interview was "What is your opinion about the role of English in being informed about the current events happening worldwide?" Answers given by 
the participants for this question are centered upon two themes. The first theme is about "diversity of sources" provided by universality of English language. To clarify this theme, S9 says: "When we surf in the internet, we can see that there are millions of global news portals and these portals are primarily using English to present the verbal or written news. Therefore, knowing English provides us a great diversity of sources to be informed about the current events happening worldwide. Instead of reading or listening to the translated versions of the original news which is limited only with our native language, we can access different sources in English providing us opportunity to comment the news from different point of views".

The second important theme pointed by the participants is "reliability of secondary or translated sources". This concern is shared by almost all the participants and S10 put his concerns into words by saying "Although I can access the news and comments about a current event in another country, I cannot completely rely on translated versions of an originally English source. Besides, I don't think that the same feeling and message can be translated $100 \%$ percent even if a perfect translation is provided lexically and grammatically. Therefore, being informed from the original source by using English is very important for $m e^{\prime \prime}$.

The last question asked in this category was "What is your opinion about associating current events happening worldwide with English courses?" When we analyze the answers given by the participants, we can see that 9 of them are positive about this idea while only S6 doesn't support the idea of associating current events happening worldwide with English courses. Positive opinions are grouped into two themes that are "increasing world knowledge" and "students' interests" while negative opinion's theme is "need for specialization". To give an example for the first theme, S7 says: "Nowadays, students from all levels are not interested in following the current events happening either in their countries or all around the world. They spend too much time in the internet but they aren't interested in current events. Therefore, if we associate current events with English courses, we can provide the students inputs useful both for learning English and increasing their world knowledge".

As for the second theme, S1 focuses on the importance of students' interests with these words: "Current events from different topics can be interesting for students and every student can find an appealing topic for himself of herself. Therefore, while implementing the idea of associating current events with English courses, students' interests should be taken into consideration. Current topics that may appeal students' interests should be given priority while planning English courses". As the only participant who object to the idea of shaping English courses around current events S6 says: "I am not in favor of associating current events with English since understanding and commenting current topics require specialization. I mean, in order for a student to write and speak a current topic in English, he or she should have enough knowledge about the topic. If a student doesn't have enough information about that topic, he or she will hesitate to participate in English courses which will end up with frustration and anxiety".

\section{Students' views about relationship between English and their current and future education}

In this category, 4 questions were addressed to the participants in order to get detailed comments on their views about the relationship between English and students' current and future education. First question in this category was "What is your opinion about the role of English in education?" Although all of the participants have a consensus on the great importance of English on their current and future education, they mainly emphasized two themes. First theme taken from participants' answers is English's being "scientific language" used all around the world. Under this theme, they also mentioned the fact that English provides both students and researchers with a great diversity of sources while studying or conducting a research. This view also matches with the views about the role of English for enhancing their world knowledge mentioned in the previous section. As an answer for this question, S1 says: "In our country, medium of instruction of some universities, including mine, is $100 \%$ English. Although it creates some troubles for the students, I am totally in favor of this implementation since English is the global 
scientific language. Besides, it is sometimes really difficult to reach good sources in my native language, Turkish. Therefore, having good skills of English facilitates accessing a great diversity of scientific sources contributing to my current and future education".

While answering this question, most of the participants mentioned that learning English is a problem for Turkish students from primary school to university. This leads us to the second theme which is "importance of background language education". Some participants stated that they are having difficulties in following English courses given during the preparatory class since their background English education was not sufficient and they believe that it affects their current and future success in terms of English education and university education as a whole. For example, S10 draws attention to this point by saying "Although I began learning English when I was a 4th grader and have been learning English for nearly 10 years, I still feel insufficient to follow my English courses which demotivates me and creates a negative feeling for my current and future education".

The second question asked in this category was "What kind of a relationship is there between your English level and success?" Participants' answers were centered upon two themes which are "direct proportion" and "effects on motivation". According to the participants, there is a direct proportion between their English level and being successful in education. To exemplify this ideas S6 says: "Before I came to preparatory class, my English level was low and I had some problems with following skill-based courses. However, as the time passed, my English level has improved and it became easier for me to follow the courses and participate in classroom activities. I think this situation will gain more importance when I start my faculty courses since all my courses will be taught 100\% English. Therefore, the more I understand the content presented in English, the more successful I will be".

Another important point made by the participants for this question is the effects of having a high or low level of English on their motivation. They also mentioned that when they feel weak in terms of their English skills, they also feel a high level of anxiety which effects their success. Answer given by S3 explains the positive and negative effects of English level on success at the same time. S3's answer is as following: "First of all, I want to give a personal example for this question. Our university's medium of instruction is English. While we were chatting with my friends before the beginning of the academic year, some of them were very nervous about their English level and they were pessimist about being successful in both preparatory class and their faculties. On the other hand, my English level has always been good enough so I was more optimistic and motivated than my friends. What I mean with this example is that our English level has an either positive or negative psychological effect on our success in education".

The third question in this category was "To what extend do you think you will benefit from English while studying for a specific course in your faculty?" Answers given by the participants can be categorized under the theme of "using in a global scale". In this regard, S6 says: "What I observe from my friends and instructors from my faculty is that they refer to different sources all around the world while they are preparing a project or presenting a topic. Therefore, it seems that I will have to read English sources too often. Besides, I already have enough information about my field and I can always access Turkish sources, so what makes difference is being able to gain more information about what is going on in my field in a global scale".

Another participant evaluates this situation from a different point of view by pointing the same theme. S2 explains his point of view with these words: "When I pass to my faculty courses, I know that we will prepare a lot of projects and presentations in English. I also want to study for master and doctorate after my graduation. All of these studies and researches require me access various sources from different countries. Today, there are hundreds of libraries and databases all around the world and the language to access them is English. Therefore, during my future studies, I believe that I will benefit from English more than I benefit from my native language, Turkish".

The last question of this category was "What is your opinion about English's being $100 \%$ medium of instruction in your university?" Participants' views about this issue has gained more importance recently 
due to increasing number of universities that prefer English as the medium of instruction. There are different views among the participants about this topic. Some participants are in favor of using English as the medium of instruction while some of them express specific concerns about it. Participants who support this idea find it challenging but beneficial. They emphasize that after being exposed to an intensive English program, it is important to continue receiving input in English within a meaningful context which is their faculty courses. S9 says: "Although it sounds very challenging for me to follow my faculty courses in English, in the long term I believe that it will help me to keep my English skills fresh and alive throughout my university education. In addition to this, receiving a diploma on which the fact that all the courses are given in English is written will provide me more chances in terms of finding a job in the future".

Participants who are critical about this idea mentioned the importance of preserving cultural identity while teaching English or using it for various purposes including as the instructional language. S1 puts his ideas into words by saying "I think using English as the medium of instruction is not a good idea since it causes degeneration of Turkish language. On the other hand, I admit the fact that it is almost impossible to access some useful resources without English. That's to say, I am totally in favor of learning English but I don't approve its being the language of instruction. Instead, useful resources can be translated into Turkish successfully and courses are given by using our native language". Another participant who shares the same opinion with S1 is S4. She says: "Although using English as the instructional language is beneficial in many ways, I believe that it causes us to move away from using our native language as properly as it should be. Therefore, we should first discuss the efficiency of Turkish courses and make students be able to use their native language efficiently. Otherwise it will be very difficult to follow instructions in English without being able to acquire our native language".

\section{Students' views about relationship between English and professional career}

The last category of the questionnaire aimed to get the participants' opinions about the role of English on their professional career. Similar to the previous categories, 4 questions were addressed in this category as well. First question of this category was "What is your opinion about the role of English on your professional career?" When we analyze the answers given by all the participants, the first theme which is emphasized most is English's being "prerequisite" to find a good job. For example, S10 says: "The world is becoming more globalized and English is the common language used in almost all the fields including commerce and so on. Therefore, not only international companies but also Turkish companies state knowing English at a level as a prerequisite to apply for the job".

The second theme taken from the answers given by some participants is "qualification". Although they agreed upon the fact that knowing English is a criterion to be qualified for a good job, they questioned and criticized this fact from a different point of view. In order to illustrate this point of view S1 says: "Today, almost every candidate for a qualified job has to know English since most of the companies regardless of their size require English as a prerequisite. I can understand why international companies require an employee to know English but local companies also ask a candidate to know English and sometimes they give more priority to English than a candidate's abilities and appropriateness for the job. I think this is not fair and risky since it is probable to hire an employee just because he or she knows English without having necessary qualifications for the job other than English".

S2 also points out the same concern mentioned by S1 by saying "Since the number of people who have a good level of English is low in our country, companies are lionizing these people. Normally, in most of the developed countries English is not attributed that much importance since citizens of these countries are given a good English language education. However, in our country although students are given a huge amount of English education, the number of qualified people in terms of English skills is still below the desired level. Therefore, knowing English becomes a great advantage to get a job. Nevertheless, I believe that there are so many employees in big companies of Turkey whose only qualification is knowing 
English and professional abilities are unsatisfactory. I mean, English shouldn't be the most important criterion to employ someone".

The second question of this category was "What kind of a relationship is there between a person's English level and job opportunities?" While answering this question, all of the participants mentioned that having a good level of English provides a great advantage to get the applied job. Therefore, "advantage" is the most frequently mentioned theme taken from this question. In addition to advantages of knowing English well, some of the participants emphasized the importance of having a certificate that proves a person's English level. They believe that certification increases the chance of getting a job that require English as a prerequisite condition. S2 says: "Big companies in Turkey require TOEFL or IELTS results and they don't accept any applications without a certificate that shows your English level even if you are competent at using English". S4 also supports this view by saying "Knowing English may not be enough for some companies. They attach importance to your projects, trainings and certificates that show your both professional and English language skills".

"What kind of steps should be taken in English language teaching in order to prepare you for your professional career?" was the third question of this category and one of the most important theme to be taken from this category is need for English for Specific Purposes (ESP) courses before students pass from preparatory class to faculty courses. Without an exception, all the participants underlined the importance of learning Vocational English as well as general English. For example, S2 says: "I believe that we should focus on Vocational English since it is more important and difficult than learning general English. Being able to use terms and concepts related to my profession and understanding special terms used in my field is very important for my education and future career. Even if we are good at general English, having a grasp of Vocational English will help us to be one step ahead". Another participant referred as S7 in this study says: "Terms regarding to sales and marketing, commercial negotiation techniques, preparing a commercial presentation, getting a price quote from a company, exchanging letters between companies and preparing reports and contracts are very important in professional career and they require knowing special language specific to business and economy in this case. Therefore, English for Vocational Purposes should be taught to students without losing time".

The last question in this category was "What is the influence of feeling yourself obliged to learn English as a prerequisite to find a good job on you?" Some participants indicate that there are motivational effects of this situation. S8 says: "At first, I was not happy to feel obliged to learn English to be successful in education and my future career. However, as I learn English and see the benefits of using English skills, I started to feel more motivated and enthusiastic to learn". S3 also states similar views by saying "Even if we don't know English, we may have a job whether good or bad. However, if our employers put English as a criterion to be promoted we shouldn't feel stressed or anxious since this criterion can provide us a chance to improve our personal skills as well as contributing to our company". Apart from positive views about this issue, some participants indicate that imposing English as a criterion for success in professional career is unfair and creates inequality among candidates and employees. For example, S6 says: "I don't find imposing English as a criterion to be employed or promoted fair since it is probable for a person whose English good to be good at his or her profession. Besides, its vice versa is also possible and a person who is good at English doesn't mean that he or she is a qualified person in his profession. Therefore, in order not to create unfairness and inequality, employers should be careful while hiring a person by judging him or her only with his English level".

\section{Discussion and conclusion}

The results of this study reveal that participants attribute great importance to the universality of English as a foreign language and they mention that this feature makes English the most important and reliable tool to access sources in order to enhance one's world knowledge and to improve their educational and professional opportunities. Although they expressed some concerns regarding 
associating cultural elements with language learning, they don't have irreparable prejudice towards a foreign culture and they find it necessary to marry language learning with cultural components. Relationship between language and culture and role of learning a foreign language on enhancing a person's cultural and world knowledge have been emphasized by different studies. In this regard, Choudhury (2013) emphasized the inextricable and interdependent relationship between language and culture. He also recommends teachers to equip students with high level of intercultural communicative competence. Purba (2011) discusses following reasons for the necessity of integrating culture into foreign language teaching process: 1 ) language and culture are inseparable: (2) teaching cultural elements facilitates language learning for learners; (3) having background knowledge about the culture of the target language is necessary for anyone to communicate successfully with the speakers of the target language.

Every language includes a new lifestyle and way of thinking. Learning a foreign language has a close relationship with learners' personality, social life and his culture shaped by their environments in which they were grown up. Therefore, learning a language is a way of cultural transmission as well. In this regard, feelings and thoughts that we want to express in a target language requires teaching culture apart from teaching that language's linguistic elements. If we can understand cultural concepts, we can also understand how people from a different culture perceives the world. In addition to this, a wellplanned foreign language teaching process will provide students a global world perspective and world knowledge with the facilitator role of language. (Alpar 2013: 104). Çiftpınar and Tanır (2013) express similar concern that some of the participants mentioned in this study which is about preserving cultural identity of learners' native language by indicating that learning a foreign language is indispensable in today's world. However, in order to facilitate Turkish students' foreign language learning process, educators should teach Turkish culture and language sufficiently since mastering in native language will is one of the elements that expedite learning a foreign language.

In terms of the role of English in education, participants appreciate English's being lingua franca in science and education and they express enthusiasm to learn it. Therefore, they support the idea of using English as $100 \%$ medium of instruction despite its being challenging due to inefficacy of their background language education. In a similar study, $\mathrm{Hu}$ (2019) focused on English-medium instruction in higher education of China. He summarized 4 studies focusing on; 1) English medium instruction (EMI) stakeholders' language ideologies, practices and management efforts; 2) Effects of EMI on Chinese students' ability to use English; 3) Classroom use of English in an established EMI Calculus course at a leading Chinese university and 4) Teacher-student interactions in Chinese EMI classrooms. The results of those studies reveal that EMI needs to be grounded in solid empirical studies. In addition to this, it is necessary for instructors and students to have adequate level of English. It also underlined that instructors should also be competent with language teaching as well as communicative strategies. Other two important topics related to each other revealed by this study are the need for carrying out needs analysis before planning language education and implementing English for Specific Purpose (ESP) courses before students move to their faculty courses so that they have prior linguistic knowledge about their fields. Needs analysis can help institutions to match the needs of their target audience with courses and programs they want to run. Any institution planning to run a new course should conduct a needs assessment survey to find out its students' needs and enthusiasm about that course. Needs analysis will help institutions analyze the short-term and long term needs of their students and in turn will be instrumental in developing their course planning strategies (Azimi \& Rahmani 2013). In a study conducted by Alsamadani (2017), it is found that receptive skills (i.e., reading and listening) were mostly focused on in ESP classes. It has been also reported that writing and reading along with speaking skills were needed more than others. The data analysis helped to determine the most important language tasks in the context of engineering studies. These results are found valuable for both ESP and subject matter teachers to enhance the quality of the ESP course taught to engineering students. 
ESP courses, on the other hand, are very useful and important for university students studying at different faculties. In the field of English Language Teaching, English for Specific Purposes (ESP) focuses on specific English language needs of the target learners and has been an important and innovative field since its first appearance in 1960s. This term refers to teaching a specific genre of English for students with specific goals. It has gained popularity over the years and more studies have been conducted focusing on different fields. ESP is target specific and focuses English teaching and learning, designed for the specific learners according to their academic and professional needs. Elements of teaching-learning process such as environment, methods, materials and contents used in ESP are not the same as in General English (Rahman 2013).

Another conclusion that can be inferred form participants' answers is the importance of intrinsic and extrinsic motivation that have great influence on the success of learning a foreign language. Participants' answers reveal that first category of the interview which is about the role of English on world knowledge is mainly about intrinsic motivation while the last two categories that are related to education and professional life are influenced by extrinsic motivation. The reason for this situation is the fact that increasing one's world knowledge and need for learning new cultures are driven by a person's own will while elements that motivate a person in education and profession may be derived from both internal and external factors. Some of the participants of this study expressed that being obliged to learn English to find a good motivates them to improve their English skills while some others find it a source of anxiety since it creates stress over them. Therefore, educators should be conscious about the impacts of motivation and anxiety on foreign language learning process. Another feeling that participants emphasize is unfairness or inequality resulting from attributing too much importance to English which results in underestimating a person's professional skills.

\section{Recommendations}

After a long period of education, university students have enough experience and background knowledge to assess their language learning journey and preparatory class is the last phase of the formal education where students are exposed to an intensive English program. Therefore, educators should take students views and concerns into consideration while planning language education. In this regard, it is recommended to conduct periodical need analysis starting from early years of education until students graduate from university since they provide valuable information about students' needs, interests and levels. As the study reveals, participants are in favor of associating current events with language learning on condition that they match with students' interests and needs. Conducting a need analysis will also help curriculum planners to decide which current topics are addressing students' interests and how to adapt them to teaching activities and materials.

The results of the study show that motivation as one of the most important affective factors plays an important role while learning English. Therefore, program designers and instructors should take necessary steps in order to create a classroom environment where students are intrinsically motivated. Extracurricular activities that focus improving students' foreign language skills should also be planned and so that the students can practice their skills in an authentic environment in which less stress is felt.

Another important issue that need analysis will lead is the idea of implementing English for Specific Purpose (ESP) courses during preparatory class so that students are provided with the chance to have prior cultural and linguistic knowledge about their field. Planning an ESP course require expertise on both English language and the field for which an ESP program is being planned to be run. Therefore, a close cooperation should be established between students, faculty members and English language instructors starting from the need analysis phase until the evaluation of the designed course.

This study also reveals that although students are positive about learning a foreign language as well as learning a foreign culture, they still have concerns about preserving their national and cultural identity. This may cause some students have prejudice against learning a foreign language and have 
negative effects on their success. Therefore, educators should be aware of this risk and emphasize the fact that learning a foreign language and its culture doesn't mean giving up one's own national identity. On the other hand, since this issue isn't one of the main topics of this study, a more detailed research focusing only on this concern is recommended so that the underlying reasons for students' concerns can be detected properly.

Apart from above mentioned recommendations that mainly address teachers and education planners, it is recommended for companies and employers to be fair and equal while evaluating the candidates that apply for a job. In other words, they shouldn't put a person's English level as the only criterion to be hired but their professional skills and abilities other than knowing a foreign language should be given equal weight.

\section{References}

Abdulhafidh, E. (2015). The role of English in present day higher education. Paper presented at $5^{\text {th }}$ International Visible Conference on Educational Sciences. Erbil: Iraq.

Alpar, M. (2013). Importance of cultural elements in foreign language teaching. The Journal of Language and Linguistic Studies, 9 (1), 95-106.

Alsamadani, H. A. (2017). Needs analysis in ESP context: Saudi engineering students as a case study. Advances in Language and Literary Studies, 8 (6), 58-68.

Azimi, M. H. \& Rahmani, R. (2013). Importance of needs assessment for implementation of e-learning in colleges of education. International Journal of Information and Computation Technology, 3 (5), 377-382.

Büyüköztürk, Ş., Kılıç E., Akgün, Ö. E. Karadeniz, Ş. \& Demirel, F. (2008). Scientific Research Methods. Ankara: Pegem A Press.

Choudhury, M. H. (2013). Teaching culture in EFL: implications, challenges and strategies. IOSR Journal of Humanities and Social Science (IOSR-JHSS), 13 (1), 20-24.

Corbin, J. \& Strauss, A. (2015). Basics of Qualitative Research: Techniques and Procedures for Developing Grounded Theory. New York, NY: SAGE Publications.

Çiftpınar, B. \& Tanır, A. (2013). Language-culture relationship and language erosion in foreign language teaching. Universe of Culture, 4 (12), 99-109.

Gokyer, N. \& Bakcak, S. (2014). Evaluating of the attitudes of university students taking English classes. Turkish Journal of Educational Studies, 1 (2), 90-125.

Hu, G. (2019). English-medium instruction in higher education: lessons from China. The Journal of Asia TEFL, 16 (1), 1-11.

Karasar, N. (2006). Scientific Research Methods. Ankara: Nobel Press.

Li, F., Ma, H. \& Wang, L. (2013). An analysis of English learning barriers of minority preparatory students and its strategies. American Journal of Educational Research, 1 (7), 267-271.

Mevzuat (2018). http://www.mevzuat.gov.tr/MevzuatMetin/1.5.2923.pdf (24 May 2018).

Rahman, M. (2015). English for specific purposes (ESP): A holistic review. Universal Journal of Educational Research, 3 (1), 24-41. DOI: 10.13189/ujer.2015.030104.

Pan, L. V. \& Akay, C. (2015). Examining foreign language learning students' attitudes and classroom anxiety levels towards foreign language courses at faculty of education. Electronic Journal of Social Sciences, 14 (55), 79-97.

Purba, H. (2011). The importance of including culture in EFL teaching. Journal of English Teaching, 1 (1), 44-56.

Yıldırım, A. \& Şimşek, H. (2013). Quantitative Research Methods in Social Sciences. Ankara: Seçkin Press.

YOK (2018). http://www.yok.gov.tr/web/guest/universitelerimiz (May 28, 2018).

Yurtseven, N., Altun, S. \& Aydın, H. (2015). An analysis on motivational beliefs of preparatory class students about learning English. The International Journal of Educational Researchers, 6 (1), 13-30. 